\title{
（125）高溫クレッール・フォルムアルデヒド樹脂の初期反應に就て
}

\section{金子、曾政 - 山下. 加代}

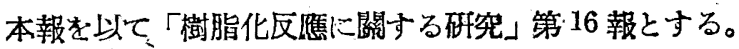

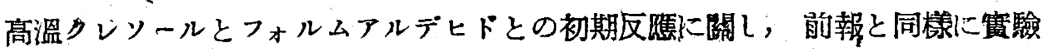
した結果を簡單に報告する。

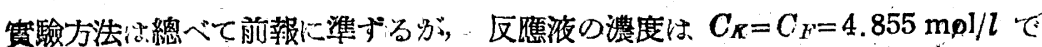
ある。

$\mathrm{HCl}$ と $\mathrm{NH}_{4} \mathrm{OH}$ 觸媒の場合の反應時間と粘度の關係を第 1 圆に, $\mathrm{NaOH}$ 觸媒 の塨合を第 1〜2 表に示す。

第 1 表 $\mathrm{N} / 2-\mathrm{NaOH}$

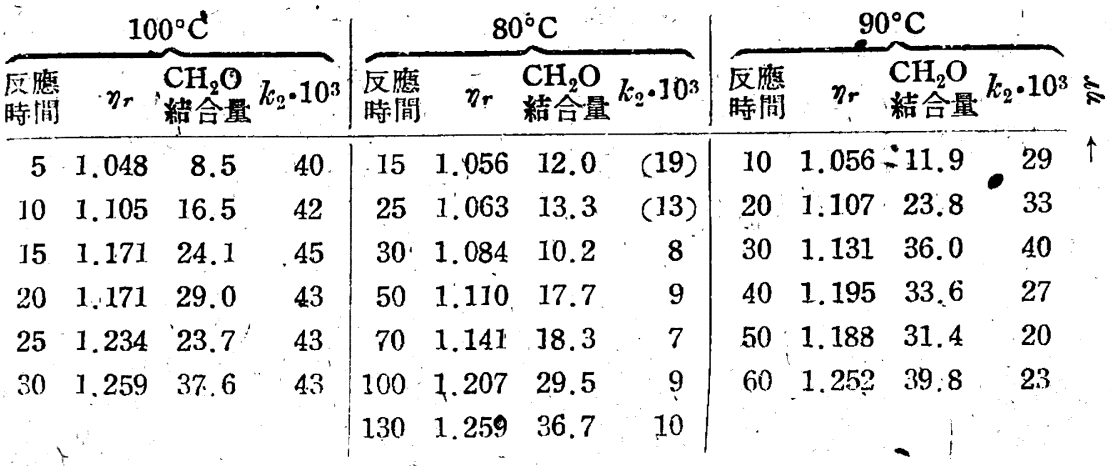

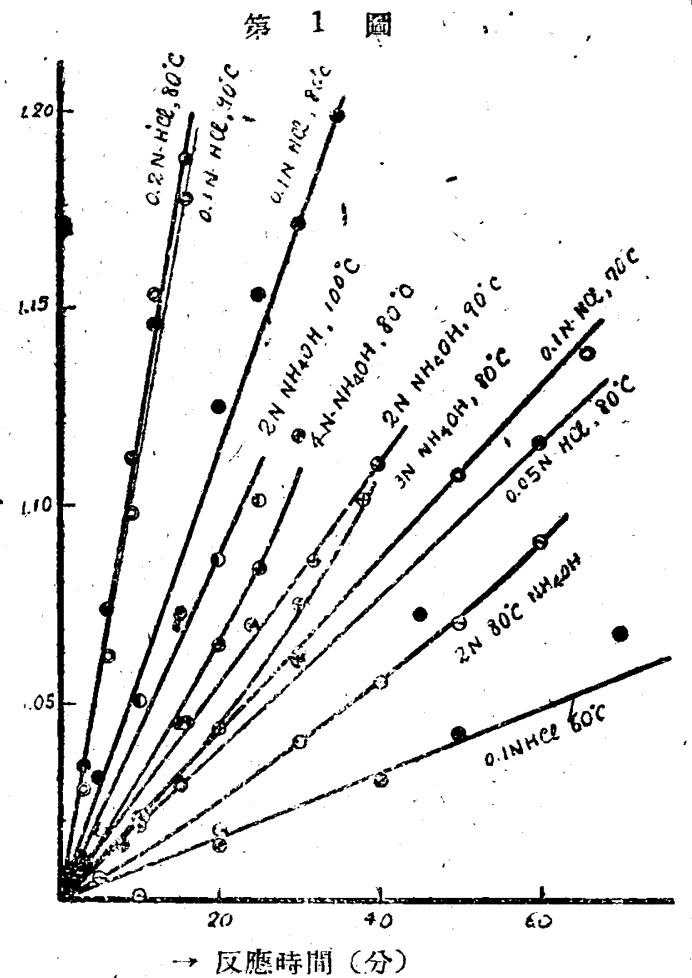

第 2 表 仅㦄溫度 $=80^{\circ} \mathrm{C}$

\begin{tabular}{|c|c|c|c|c|c|}
\hline & \multicolumn{2}{|c|}{$1 N$} & \multicolumn{2}{|c|}{$0.75 N$} \\
\hline 反娩時間 & $\eta_{r}$ & 反應時間 & $\eta_{r}$ & 反庥時問 & $\eta_{r}$ \\
\hline 5 & -11237 & 10 & 1.159 & $10^{\circ}$ & 1.096 \\
\hline 10 & 1.316 & 20 & 1.246 & 20 & 1.159 \\
\hline 15 & - 1,378 & 30 & 1.282 & 30 & 1.215 \\
\hline 20 & 1.414 & 40 & 1.350 & 50 & 1.278 \\
\hline 25 & 1.444 & 50 & 1.387 & 70 & 1.342 \\
\hline 30 & 1.486 & 60 & 1.412 & 90 & 1.386 \\
\hline
\end{tabular}

第 1 圖及び第 1〜2 表の結果より溫度係數及び活性化䓡を計算 ナれば第了裴の如くでむる。

第 3 表

\begin{tabular}{|c|c|c|c|c|c|c|}
\hline 觸，媒 & $\eta_{r}$ & 溫度範圍。 & 溫度保䧶 & 活性化熟 & (kcal) & \\
\hline \multirow[t]{2}{*}{$\mathrm{HCl}$} & 1.05 & $90 \sim 80$ & 2.04 & 38.2 & ' & $\bullet$ \\
\hline & & $80 \sim .0$ & 2.76 & 24.5 & & \\
\hline \multirow[t]{2}{*}{$\therefore$} & $i$ & $70 \sim 60$ & 2.63 & 21.7 & & \\
\hline & & 本均 & 2.48 & 21.5 & & \\
\hline \multirow{5}{*}{$\underset{\mathrm{NH}_{4} \mathrm{OH}}{ }$} & 1.04 & $100 \sim 90$ & 1.56 & 12.0 & . & \\
\hline & & $90 \sim 80$ & 2.04 & 18. 1 & & \\
\hline & 1.08 & $100 \sim 90$ & 1.56 & 11.9 & & \\
\hline & & $90 \sim 80$ & 1.89 & 16.2 & & \\
\hline & & 平 均 & 1.84 & 14.6 & & \\
\hline
\end{tabular}

$$
\begin{aligned}
& \mathrm{NaOH} \quad 1.15 \quad 100 \sim 90 \quad 2.21 \quad 21.2 \\
& 90 \sim 80 \quad 2.22: \quad 20.2 \\
& 1.25 \cdot 100 \sim 90 \cdot 2.11 \quad 20.0 \\
& \text { 本 玸 } \frac{2.11}{2.16} \cdot \frac{18.9}{20.1} \\
& \mathrm{NaOH} \text { ，滴定沾 } 100 \sim 90 \text { (10.7) } \\
& 90 \sim 80 \quad(30.5) \\
& \text { 平 均 }(20.6)
\end{aligned}
$$

邬ちファノールの昜合より若千不規則ではあるが，知張り $\mathrm{NH}_{4} \mathrm{OH}$ のが活性化熱が小さ、, 且總てを通じてフェクールの 場合と同じ程度の值炎示してるる。 $\mathrm{CH}_{2} \mathrm{O}$ の消費量と粘度上昇の 關係も略司䤼である。

觸煤濃度に關しては $\mathrm{NaOH}$ の場合は添加量による影辢はつェ ノールす場合より大きく，1Nではクレンールの方が早いが， $0.5 \mathrm{~N}$ では逆である。尤もこの際 $C_{K} \cdot C_{F}$ が $C_{P} \cdot C_{F}$ より若干小

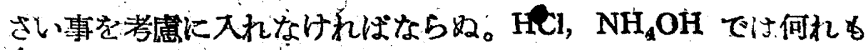
觸某添加量の影䈉はフェノールの時と大差なからた。

$$
\text { 要 . 約 }
$$

演溫クレッール樹脂の初期反㢈を检し，反應形式，溫度係數，

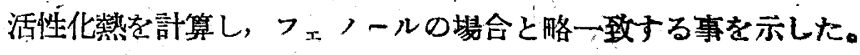
（旅順工大應化：昭和 21. 3. 25 涭理）

（126）低溫クレソール・フォルムアルデヒド樹脂の初期反應に就て 金子冒政 - 山下 加代

本研究を「樹脂花反應に關する研究」第 17 報とする。 本報は滿洲產低溫クレソールとフォルムアルデヒドとの初期反 應に關する覥驗結果である。
先づ低沮クレンールを蒸溜して，各溜分の沃度添加を行ひ头の 結果を得た。 
第 1 装

溜出溫度 $\quad 200 \sim 205 \sim 210 \sim 215 \sim 220 \sim 230 \sim 233$

クレソール1モ

几に對し反佂す

る $\mathrm{I}_{2}$ $ル ル$ 效

2.31

2.22

$\begin{array}{llll}2.09 & 1.95 & 1.93 & 1.64\end{array}$

前報高溫クレンールは 2,61 〔， 乙より計算したメタクレソー
ル分は 61.2\% である。同じ計算を低溫クレンールに就て行ふと 200〜205\%Cのはメタクレソール分 31.4\%，次は $21.8 \%$ ，その 决は 8.8\% である。晌本法ではオルトやパラ以下のものがあれば 當然メタ分が少くでる事を注意すべきである。

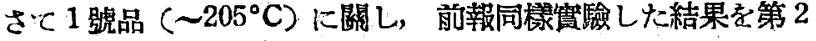
韯に示寸。

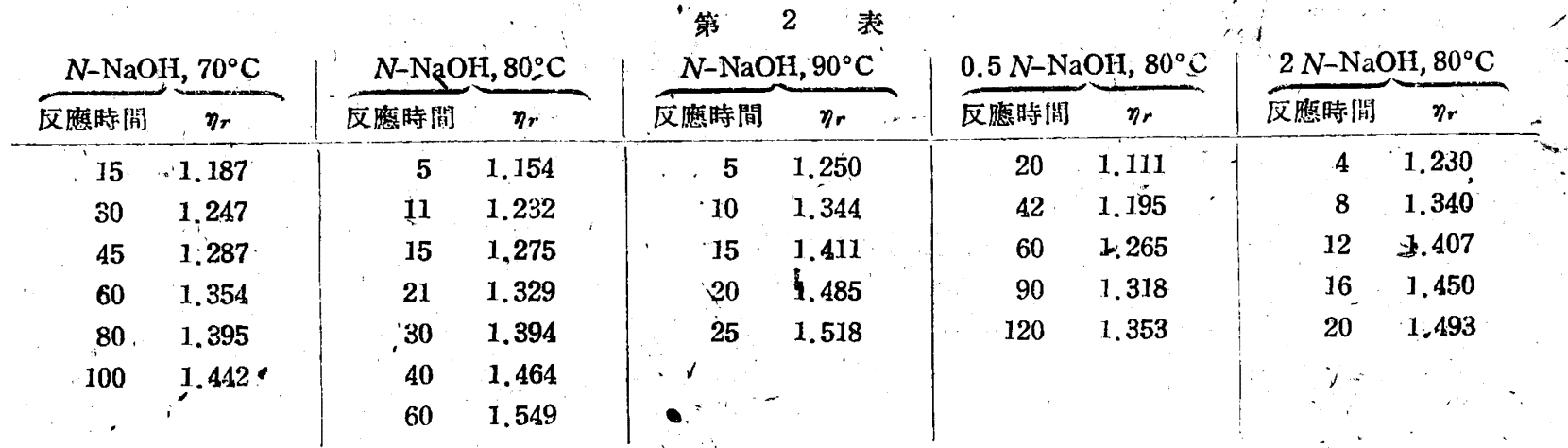

表より計算した 1 號品の溫度係數注第 3 表の如くである。

\begin{tabular}{|c|c|c|c|c|}
\hline$\eta_{r}$ & 1.25 & 1.35 & 1.45 & 平均 \\
\hline 溫度㛊數 $\left\{\begin{array}{l}90 \sim 80 \\
80 \sim 70\end{array}\right.$ & $\begin{array}{l}2.17 \\
2.43\end{array}$ & $\begin{array}{l}2.20 \\
2.62\end{array}$ & $\begin{array}{l}2.14 \\
2.63\end{array}$ & $\begin{array}{l}2.17 \\
2.56\end{array}$ \\
\hline 活性:化缹 $\left\{\begin{array}{l}90 \\
80 \mathcal{Z}_{70}^{80}\end{array}\right.$ & $\begin{array}{l}19.7 \\
21.4\end{array}$ & $\begin{array}{l}20.0 \\
23.3\end{array}$ & $\begin{array}{l}19.3 \\
23.4\end{array}$ & $\begin{array}{l}19.7 \\
22.7\end{array}$ \\
\hline
\end{tabular}

、夾に低溫クレンールの各部分及び高溫クレッールの比較である， が, 低溫クレソールを 1 號品 $\left(\sim 205^{\circ} \mathrm{C}\right), 2$ 號品 $\left(\sim 220^{\circ} \mathrm{C}\right), 3$ 號 品( $\left.\sim 240^{\circ} \mathrm{C}\right)$ と分類し， $\mathrm{NaOH}$ 觸媒の場合の初期反應を見ると 第 J〜2 圖の如くなり，粘度上昇割合は 3 號品が一番早いが， フ ェノールに對するフォルムフルデヒドの結合量が少い。

\section{第 1 圆}

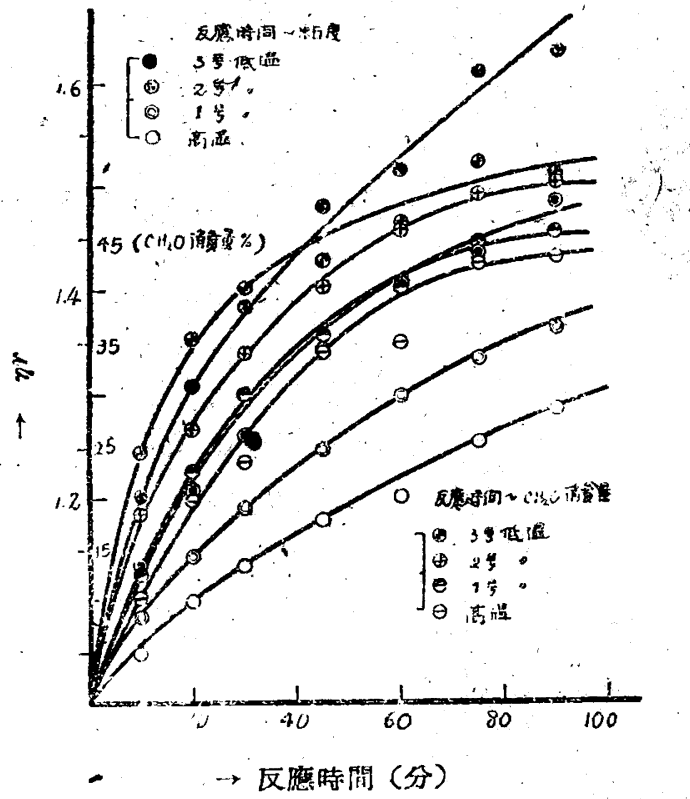

何本蜜驗では初めにアルコーれを $5 \mathrm{cc}$ 加へて反應せしめた。 又 $\mathrm{HCl}$ 及び $\mathrm{NH}_{4} \mathrm{OH}$ の時は乳化の第，規則的な結果が得られな がンた。

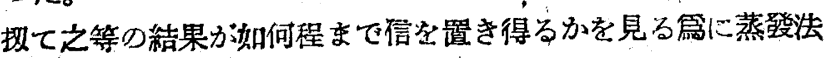
に上り算際澍脂老作つてみた。その埸合の收量となセトン溶液 を $25^{\circ} \mathrm{C}$ で湘定した粘度より著者等の粘度式に從て計算した比容 䅡 $\varphi_{k}$ と第 4 表に示す。之は $32.5 \%$ (重量)のフォルマリンと

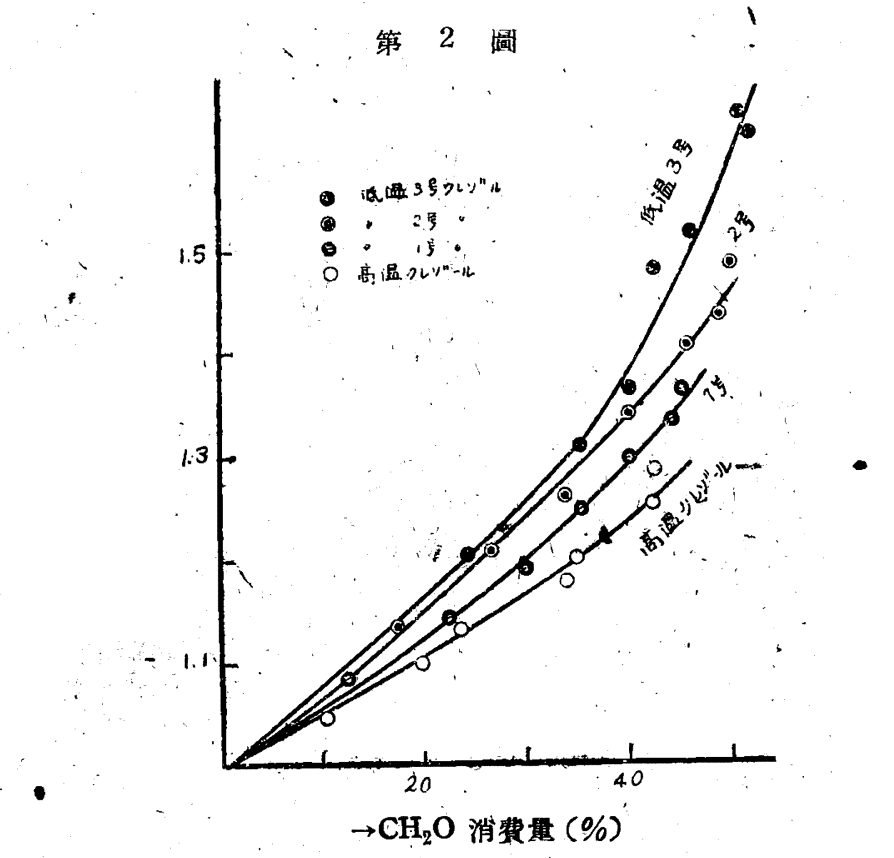

クレソールとを等分子比にとり，その $40 \mathrm{~g}$ にチチアルコール

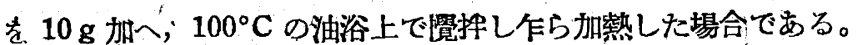

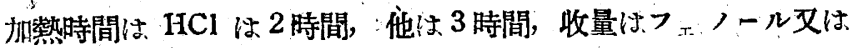
クレンールに對する重量\%で示してある。

\begin{tabular}{|c|c|c|c|c|c|c|c|c|}
\hline \multirow{2}{*}{\multicolumn{2}{|c|}{ 㑤兹 媒 }} & & \multicolumn{2}{|c|}{$4 \mathrm{~N}-\mathrm{NH}_{4} \mathrm{OH}$} & \multicolumn{2}{|c|}{$1 \mathrm{~N}-\mathrm{HCl}$} & \multicolumn{2}{|c|}{$2 \mathrm{~N}-\mathrm{NaOH}$} \\
\hline & & & est & $\theta_{2}$ & 监船 & $\varphi_{i}^{\prime}$ & & $\varphi_{k}$ \\
\hline & - & $\pi$ & 89 & 0.95 & 121 & 1. 45 & 104 & 1. 18 \\
\hline 溫クレ & & U & 88 & 0.90 & 121 & 1.30 & 118 & 1.20 \\
\hline 溫 & 1 & 雅 & 92 & 0.97 & 118. & 1.35 & 116 & 1.22 \\
\hline "I & 2 & 㟲 & 74 & 0.92 & 109 & 1.2 & 116 & 1.78 \\
\hline 11 & 3 & 枵 & 102 & 0.88 & 95 & 1.36 & 118 & 2.44 \\
\hline
\end{tabular}

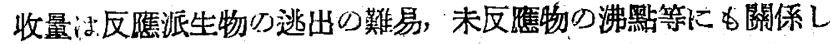
之のみでは充分なる考察をなし得ないが, 比容積が大きければ反 應がより淮んでるるものと判断されるから， $\mathrm{NaOH}$ の場合には前 項の事筫が確認される。向 $\mathrm{NaOH}$ の時には 2 號品は”7.3\%，3 號品は $24.8 \%$ のアセトン்不溶部分があつた。 
要 約

渋洲產の低溫クレシールにつき, 分溜溫度と活性度の關係に就

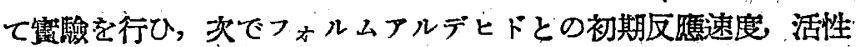
化䂑，生成樹脂のアセトン溶液の粘度等に關して試驗し，全般を
通し1號品は高溫クレッールK飞敵し，又 $\mathrm{NaOH}$ 觸媒の場合火 は逆に高沸䃜のもの徨，反應速度大なる事を示した。

試料を惠與せられたる挴順化學工業所汇梁起なる謝意を：表す。 （旅順工大雇化：昭和 21. 3. 25 受理）

\section{$(127)$}

\section{覧酸觸媒フェノール樹脂の初期反應に及ほす配合比の影響に就て}

\section{红金子曾政・藤 㷊平}

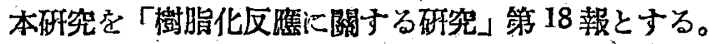

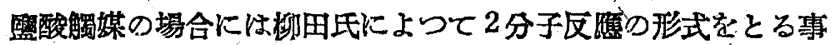
が指定されてるるにも拘らず，既報つ如くCP・CF 䅪のを一定に して $C_{P} / C_{P}$ を等化せしめる.と反應の速度か異なる。即ちこの種 の反應恃正則な2 分子反礁と見るよりは可なり複雜な因子を有す

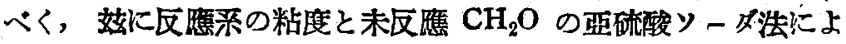

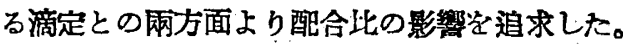

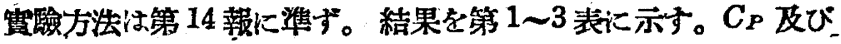

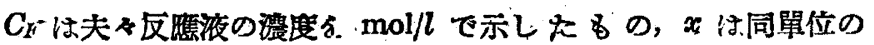
$\mathrm{CH}_{2} \mathrm{O}$ 消費量, $k_{2}$ は 2 分子反應として假化,

$$
\frac{d x}{d t}=k_{2}\left(C_{P}-x\right)\left(C_{F}-x\right)
$$

に依り計算した速唐恒數で要る。㷳溫度は總て $80^{\circ} \mathrm{C}$ でする。

\begin{tabular}{|c|c|c|c|c|c|c|c|c|c|c|c|}
\hline \multicolumn{4}{|c|}{$C_{P}=C_{F}=5$} & \multicolumn{4}{|c|}{$C_{P}=C_{F}=4$} & \multicolumn{4}{|c|}{$\dot{C P}=C_{P}=3$} \\
\hline 反應時間 & $\eta_{r}$ & $x$ & $k_{2} \cdot 10^{4}$ & 反應時間 & $\eta_{r}$ & $x$ & $\widehat{k_{2} \cdot 10^{4}}$ & 反應時間 & $\overline{\eta_{r}}$ & $x$ & $k_{2} \cdot 10^{4}$ \\
\hline 10 & 1.112 & 0.858 & 41 & 20 & 1.032 & 1.313 & 61 & 60 & 1.018 & 1. 659 & 69 \\
\hline 20 & ]. 209 & 1.151 & 30 & 40 & 1.068 & 1.516 & 38 & 120 & 1.053 & 1.682 & 35 \\
\hline 20 & 1.337 & 1.407 & 26 & 60 & 1.110 & $1.6 \mathrm{I} 8$ & 28 & 180 & 1.075 & 1.754 & 26 \\
\hline 40 & 1.421 & 1.727 & 26 & 80 & 1.143 & 1.671 & 22 & 240 & 1.096 & 1.772 & 20 \\
\hline 50 & J. 546 & 1.8 .48 & 23 & 100 & J. 183 & 1.833 & 21 & 300 & 1. 122 & 1.806 & 17 \\
\hline 60 & 1.644 & 2.013 & 23 & 120 & 1.224 & 1.915 & 19 & 360 & 1.143 & 1.870 & 15 \\
\hline 70 & 1.728 & 2.179 & 22 & 140 & 1.255 & 1.987 & 18 & 420 & 3.149 & 1.893 & 14 \\
\hline - 80 & 1.914 & 2.416 & 27 & & & & & & & & \\
\hline
\end{tabular}

\begin{tabular}{|c|c|c|c|c|c|c|c|c|c|c|c|}
\hline \multicolumn{4}{|c|}{$C_{p=5}, C_{y}=4$} & \multicolumn{4}{|c|}{$C_{T}=5, \quad C_{l^{\prime}}=3$} & \multicolumn{4}{|c|}{$C_{f}=5, \quad C_{4}=2$} \\
\hline 反照時閒 & $\eta_{r}$ & $x$ & $k_{2} \cdot 10^{4}$ & 反應時間 & $\eta_{r}$ & $x$ & $k_{2} \cdot 10^{4}$ & 区應時閣 & $\eta_{r}$ & $x$ & $k_{2} \cdot 10^{4}$ \\
\hline 10 & 1.062 & 1.114 & 45 & 15 & 1.064 & 1.321 & 91 & 20 & 1.024 & 1.178 & 103 \\
\hline 20 & 1.124 & 1.358 & 49 & 30 & 1.119 & 1.468 & 54 & 40 & 1.038 & 1.219 & 55 \\
\hline 30 & 1.204 & 1.490 & 38 & 50 &, 1.187 & 1.592 & $37^{\prime}$ & 60 & 1.070 & 1.287 & 41. \\
\hline 40 & 1.245 & 1.622 & 32 & 70 & 1.266 & ]. 682 & 29 & 90 & 1.111 & 1.321 & 29 \\
\hline 55 & 1.336 & 1.821 & 28 & 90 & 1.317 & 1.802 & 26 & 120 & 1.146 & 1.404 & 25 \\
\hline 70 & 1.437 & 1.930 & 24 & 110 & 1.420 & J.942 & 25 & 165 & 1.204 & 1.468 & 26 \\
\hline & & & & & & & & 210 & 1.245 & 1.475 & 20 \\
\hline
\end{tabular}

\begin{tabular}{|c|c|c|c|c|c|c|c|c|c|c|c|}
\hline \multicolumn{4}{|c|}{$C_{p}=4, \quad C_{F}=5$} & \multicolumn{4}{|c|}{$C P=3, \quad C_{F}=5$} & \multicolumn{4}{|c|}{$C_{r=2}, C_{F}=5$} \\
\hline 区應時間 & $\eta_{r}$ & $x$ & $k_{2} \cdot 104$ & 反㤫時間 & $\eta_{r}$ & $x$ & $k_{2} \cdot 10^{4}$ & 反應時間 & $\eta_{r}$ & $x$ & $k_{2} \cdot 10^{\prime}$ \\
\hline 15 & 1.058 & 1.027 & 43 & 30 & 1.045 & 1.573 & 61. & 60 & 1.027 & 1.731 & 88 \\
\hline 30 & 1.102 & 1.294 & 30 & 60 & 1.076 & 1.629 & 32 & 120 & 1.059 & 1.754 & $46^{\prime}$ \\
\hline 45 & 1.169 & i. 437 & 24 & 90 & 1.129 & 1.765 & 25 & 180 & ]. 092 & 1.825 & 37 \\
\hline 60 & 1.224 & 1.592 & 21 & 120 & 1.170 & 1.915 & 22 & 240 & 1.114 & 1.953 & 45 \\
\hline 75 & 1.289 & 1.776 & 20 & 150 & 1.204 & 1.976 & 19 & 300 & 1.137 & 1.814 & 22 \\
\hline 90 & 1.355 & 1.938 & 19 & 180 & 1.270 & 2.055 & 17 & 360 & 1.176 & 2.058 & - \\
\hline 105 & 1.293 & 2.036 & 18 & 210 & 1.329 & 2.480 & 25 & & & & \\
\hline
\end{tabular}

之等の結果によれば反應液の $C_{P}$ 及び $C_{k^{p}}$ が大なる時注 $k_{2}$ が 略一定となるが， $C_{P}^{0} C_{F}$ の積，殊に $C_{P}$ が小さくなるにつれて 反應の初期に於て粘度は殆ど上景せずに $\mathrm{CH}_{2} \mathrm{O}$ の消費が坯大す る傾向が顯著となる。との傾向は $C_{P}=0$ の時も同詠であつて， $C_{P}$ 孝管化させた時の比較を第 1 圆に示す。向 $C_{P}=0$ の時の絬度

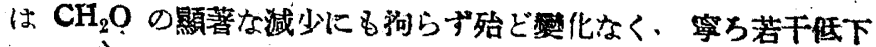
の傾向を示した。

倘見掛けの反雔速度 vが

$$
v=k \cdot C_{P^{\alpha}}^{\alpha} \cdot C_{F}^{\beta}
$$

なる關係を有するものとして第 1〜3 表より $\alpha=2.5, \beta=1.6$ を 